\title{
A Comparative Study Of Nicotine Effect On The Liver Of Albino Rat
}

\author{
Mamdouh A. Ghaly; El Sayed G. Khedr And Ahmed Abdel Aleem \\ Histology Department, Faculty Of Medicine, Al - Azhar University
}

\begin{abstract}
We have studied the effect of cigarette smoke inhalation versus subcutanous nicotine injction on the liver of 40 adult male albino rats. Animals were divided into; cigarrete inhalation group and subcutaneous nicotine injection group. Inhalation group was subdivided into 5 subgroups ; three groups inhaled the smoke of two cigarettes three times a day in a closed chamber for 1,2\&3 weeks respectively; a group of recovery after inhalation and a control group. The nicotine injection group was also subdivided into 5 subgroups; three groups were injected subcutaneously with $0.1 \mathrm{ml}$ of $1 \%$ nicotine every two days for $1,2 \& 3$ weeks respectively; a group of recovery after injection and a control group.Rats were sacrificed at the determined durations and the liver was subjected for preparation of 6 microns paraffin sections. Microscopic examination of paraffin sections stained with H\&E; Masson trichrome and PASwas done and interpreted with the image analyzer. Several histological findings such as degenerative changes in hepatocytes, cellular infiltration, periportal fibrosis, and congestion of both central and portal veins have been noticed. Also, histochemical P.A.S. reaction has showed marked decrease in both groups. The mean optical density (O D) of P A S in hepatocytes of cigarette group was $(0.31 \pm 0.02)$, and that of nicotine group was $(0.26 \pm 0.03)$, which were significantly lower than that in the control group with mean O.D. $(0.54 \pm 0.5)$ and $(0.51 \pm 0.03)$ respectively. In conclusion; the inhalation of nicotine in the form of cigarette smoke resulted in deteriorative changes in the liver of the male adult albino rat more than nicotine injected subcutaneously, and these changes was partialy reversed shortly after withdrawal.
\end{abstract}

\section{Introduction}

Nicotine is the main component of tobacco smoke, and failure to quit smoking is virtually attributed to its addictive potential, which is similar to that of opium and alcohol (Henningfield et al. 1988). It is known that smokers are relatively having a higher morbidity and/or mortality rate than non-smokers. Exposure to environmental tobacco smoke (ETS) "passive smoking" is also harmful to non-smokers' (Knudson et al, 1989a). The US environmental protection agency (EPA) classified ETS as a class-A carcinogen, as they are

highly susceptible to cancer (Benowitz, 1986).

Burning of tobacco generates about 4000 components, the most famous one of them is the tar which is a dark brown material, contains all the particulate phase of the smoke that includes nicotine, phenols, hydrocar bons, aldehydes, ketons, organic acids, and alcohol. Tar contains also a condensable amount of the gas phase. that includes some toxic gases, such as cyanides and carbon monoxide (Byrd,1991), and irritant gases as 
acrolin (Walker \& Kiefer, 1979). Moreover, tar contains also some carci nogens, such as benzopyrene (Armitage et al., 1975). Most of the carcinogenic compounds are not present in the native tobacco leaflets, but formed by pyrol ysis due to burning temperature. Also, the carcinogenic potential of tar is higher than the effect of each of the isolated substances. Nicotine, is colou rless, volatile, and highly toxic natural liquid alkaloid that turns brown and acquires the odour of tobacco on exposure to air. Nicotine is rapidly and extensively metabolised in the liver, and to a lesser extent in the lungs and kidneys (Gorrod and Jenner, 1975). Renal excretion of nicotine accounts for about $70-75 \%$ of total elimination (Rosenberg et al., 1980). Nicotine is also excreted in the milk of lactating women who smoke (Goodman and Gilman, 1991).

Nicotine has a divers effect on most if not all the body organs and/ or systems including respiratory system (Dalbey et al, 1980), cardiovascular system (Benowitz, 1988), central nerv ous system and skeletal muscles (Benowitz, 1986), endocrine system (Goodman and Gilman, 1991), bone minerals (Daniell 1976), urinary system (Auerbach and Garfinkell, 1989), and male and female genital systems (Kaufman 1980).

Chang and colleagues (1990) have noticed a prominent loss of the gastric mucosa, with bleeding ulcers in nicotine treated animals. Moreover, cigarette smoke could inhibit pancreatic and hepatic bicarbonate secretion (Konturek et al., 1971). Dubick and co-workers (1987-a) have reported that cigarette smoking could increase the content of digestive enzymes in the pancreas, as well as their basal and secretagogueinduced release. In addition to nicotine, tobacco smoke contains other cytotoxic agents, which could affect the exocrine pancreatic function (Sanakaran et al., 1985). Several studies have evaluated the pharmacological, biochemical and pathological changes induced by cigarette smoking and nicotine. However, studying the morphological, and histological changes in the liver are very uncommon. The present study aimed to reevaluate the histological, as well as the histochemical changes in the adult albino rat's liver under the effect of cigarette smoke inhalation and nicotine injection .

\section{Materials and Methods}

In the present study, forty adult male albino rats were used, and were divided equally into 2 main groups; cigarette inhalation, and nicotine injec tion groups. Cigarette inhalation group: was subdivided into five subgroups, four of which were used as experim ental groups, and one was used as a control. The experimental rats in groups I, II and III were inhaled cigarette smoke for 1, 2, and 3 weeks respec tively. While group IV was left 2 weeks without smoking after 3 weeks of cigarette inhalation. The inhalation was performed in a special closed inhalation chamber and the dose was $6 \mathrm{mg} /$ day gained form burning of two Cleopatra super cigarettes( each containing $1.0 \mathrm{mg}$ nicotine and $15 \mathrm{mg}$ tar) three times a day.

Nicotine injection group: was subdivided into five subgroups, four of them were used as experimental groups, and one was used as a control. The experimental rats in groups VI, VII and VIII were injected subcutaneously with $0.1 \mathrm{ml}$ of nicotine $1 \%$ for 1,2 , and 3 weeks respectively. While group IX was left without nicotine injections for 2 weeks, as a recovery period, after 3 weeks of nicotine administration. Nicotine powder was obtained from the 
laboratort of faculty of pharmacy, cairo univeristy and the used solution was freshly prepared in isotonic saline. The dose of injected nicotine was calculated according to Hass et al., (1966) to contain the same amount of absorbed nicotine during cigarette smoke inhala tion in the experiment .

Animals were weighed every week all over the experiment. After 1, 2, 3 and 5 weeks of the experiment, the animals were sacrificed whereas the livers were dissected, fixed, and proce ssed through paraffin technique to prepare 6 microns thickness sections. Different histological and histochemical procedures were employed, such as Haematoxylin and Eosin, and Masson's trichrome to study the morphological changes and Periodic acid Schiff techn ique to study the possible histochemical changes.

\section{Results}

The weight records showed that the rats inhaled cigarette smoke and those injected with nicotine revealed a significant decrease in their body weight. However, during the recovery period a progressive increase in body weight was noticed (Table 1; fig. 1)

In the earlier two weeks of cigarette smoke exposure hepatic pare nchyma showed variable grades of degeneration. Thus, areas of degener ation appeared among apparently nor mal hepatic cells starting peripherally around the portal tracts in zone I then progressed to zones II and III. The affected hepatocytes were large and polyhedral showing sharply defined vacuoles of variable size with reduced the cytoplasm and with indented nuclei. denoting fatty change. Sometimes, the cytoplasmic envelope around the large vacuoles ruptured and coalesced to from extracellular fat. A confined number of hepatocytes showed signs of necrosis in the from of pyknosis of their nuclei (plate II,D ).

By the end of the $3^{\text {rd }}$ week of experiment, the liver showed marked degeneration and localized areas of necrosis. Most of hepatocytes in the necrosed areas showed pyknosis and karyorrhexis while few cells were devoid of their nuclei (Karyolysis) with vacuolated or darkly eosinophilic cyto plasm. Kupffer cells became more prominent, invading sinusoidal spaces and inbetween degenerating cells (plate II,F). Moreover, periportal fibrosis and cellular infiltration. (plate I,B)

Following abstinence of smoking for 2 weeks, lymphocytic infiltration in hepatic tissue was less evident and hepatic architecture started to regain the normal pattern. However, areas of liver showed a less identified manifestation of recovery. The persistent lesions thro ugh the 2 week recovery period were degeneration of hepatocytes and prom inence of Kupffer cells (plate III ,B).

The most remarkable effect of nicotine injections during the $1^{\text {st }} 2$ weeks of experiment, was the ballooning degene ration which affected the majority of the liver cells starting in zone I, zone II and lastly zone III (plateII,D). Most of hepatocytes showed mild affection in the form of swollen cells with pale cytoplasm (cloudy swelling) and vacu olated cells with normal nuclei (hydropic degeneration). While few cells contained sharply defined fat vacuoles with their nuclei indented denoting most probably fatty changes that is called fatty degeneration. (plate II ,C ).

The degeneration of the hepato cytes progressed to vacuolar necrosis bringing about a considerable distortion of normal lobular architecture. The nuclei of hepatocytes became more pyknotic with variable sizes and might take an irregular shapes. Kupffer cells 
became more prominent invading sinusoidal spaces(plateII,E). Moreover, expanded portal tracts with dilatation and congestion of their portal veins appeared after 1 week of nicotine injec tions and became more prominent after 3 weeks (plateII,A). Focal areas of liver lobules were still attaining almost normal structure. Periportal inflamma tory infiltration of mononuclear cells mainly lymphocytes, were prominent during the earlier weeks of experiment (plate I,D). A two weeks recovery from nicotine was manifested by the appe arance of regenerative areas surrou nding central and portal veins. This was accompanied by a progressive decrease of inflammatory cellular infiltrate (plateIII,A).The hepatocytes of cigarette group showed gradual decrease in their intracellular PAS positive materials. During the $1^{\text {st }} 2$ weeks of the experi ment, the hepatocytes in zone III of hepatic lobules showed moderate PAS reaction, while the degenerated cells at the periphery of the lobules in zone I showed weaker PAS reaction. At the end of the $3^{\text {rd }}$ week of cigarette inhalation the hepatic lobules showed weak PAS reaction (plate III, D). Moderate PAS reaction was detected in zone I during the recovery period. A remarkable decrease of PAS reaction was observed also in the liver at the end of the $3^{\text {rd }}$ week of nicotine injection. (plate III, C).

Nevertheless, it should be ackno wledged that changes were not widely distributed all over the whole liver lobules. Focal areas of liver lobules were still attaining almost normal structure. At the end of the $2^{\text {nd }}$ week of recovery, generalised increase in the glycogen granules was observed, and was partially condensed in the periphery of the hepatic lobules (plate III E\&F). A decrease in optical density of PAS from groups I and II to group III in inhalation group if compared to the control group $\mathrm{V}$ was observed. While in the recovery group IV the optical density return again towards normal levels. However groups VI and VII in nicotine animals showed gradual decrease in the optical density with maximum decrease in group VIII. Table (2).

In the cegarette inhalation group III the mean optical density ofPAS in

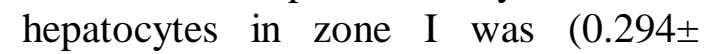
$0.015)$ which was lower than that in zone II $(0.314 \pm 0.021)$ and in zone III $(0.332 \pm 0.012)$. Opposite results was optained in the recovery group IV where the mean optical density of hepatocytes in zone I was $(0.467 \pm$ $0.013)$ which was higher than that of zones II \& III $(0.446 \pm 0.008)$ and $(0.437 \pm 0.004)$ respectively (Table 2$)$.

In the nicotine group VII the mean optical density of PAS in hepatocytes in zone I was $(0.35 \pm .01)$ which was lower than that in zone $\mathrm{II}(0.37 \pm .01)$ and in zone III $(0.39 \pm .01)$.In the recovery group IX the mean optical density of PAS in hepatocytes in zone I was $(0.45 \pm .01)$ which was higher than that of zones II \& III $(0.44 \pm .01)$ and $(0.43 \pm .02)$ respectively Table 2$)$. 
Table (1): represent the mean Values of body weigh \pm Standard Deviation, in grams. Experimental groups versus controls: Significant change $(\mathrm{P}<0.05)$.

\begin{tabular}{|c|c|c|c|c|c|c|}
\hline \multirow{3}{*}{ Duration } & \multicolumn{3}{|c|}{ Cigarette Animals } & \multicolumn{3}{|c|}{ Nicotine Animals } \\
\hline & $\begin{array}{c}\text { Groups } \\
\text { I,II,III } \\
\text { \&IV }\end{array}$ & $\begin{array}{c}\text { Group } \\
\mathbf{V}\end{array}$ & \multirow[t]{2}{*}{$\begin{array}{c}\text { Significance } \\
\text { (P-value) }\end{array}$} & $\begin{array}{l}\text { Groups } \\
\text { VI,VII,VIII } \\
\text { \&IX }\end{array}$ & $\begin{array}{l}\text { Group } \\
\mathrm{X}\end{array}$ & \multirow{2}{*}{$\begin{array}{l}\text { Significance } \\
\text { (P-value) }\end{array}$} \\
\hline & \multicolumn{2}{|c|}{ Mean \pm S.D. } & & \multicolumn{2}{|c|}{ Mean \pm S.D. } & \\
\hline starting & $\begin{array}{r}141.25 \\
\pm 17.84 \\
\end{array}$ & $\begin{array}{l}145.0 \\
\pm 20.82 \\
\end{array}$ & 0.756 & $\begin{array}{c}142.5 \\
\pm 19.83 \\
\end{array}$ & $\begin{array}{l}140.0 \\
\pm 8.16 \\
\end{array}$ & 0.703 \\
\hline 1 week & $\begin{array}{r}141.25 \\
\pm 17.84 \\
\end{array}$ & $\begin{array}{r}145.0 \\
\pm 20.82 \\
\end{array}$ & 0.756 & $\begin{array}{c}145.0 \\
\pm 18.97 \\
\end{array}$ & $\begin{array}{c}145.0 \\
\pm 10 \\
\end{array}$ & 1.0 \\
\hline 2 weeks & $\begin{array}{r}143.33 \\
\pm 15.57 \\
\end{array}$ & $\begin{array}{c}155.0 \\
\pm 12.91 \\
\end{array}$ & 0.187 & $\begin{array}{r}145.83 \\
\pm 17.22 \\
\end{array}$ & $\begin{array}{c}152.5 \\
\pm 5 \\
\end{array}$ & 0.263 \\
\hline 3 weeks & $\begin{array}{l}141.25 \\
\pm 18.08\end{array}$ & $\begin{array}{c}165.0 \\
\pm 12.91 \\
\end{array}$ & $\underline{0.03}$ & $\begin{array}{c}143.75 \\
\pm 22\end{array}$ & $\begin{array}{r}160.0 \\
\pm 8.16 \\
\end{array}$ & 0.095 \\
\hline 4 weeks & $\begin{array}{l}150.0 \\
\pm 21.6\end{array}$ & $\begin{array}{r}172.5 \\
\pm 9.57 \\
\end{array}$ & 0.127 & $\begin{array}{c}155.0 \\
\pm 26.46\end{array}$ & $\begin{array}{r}170.0 \\
\pm 8.16 \\
\end{array}$ & 0.346 \\
\hline 5 weeks & $\begin{array}{l}160.0 \\
\pm 21.6\end{array}$ & $\begin{array}{l}182.5 \\
\pm 9.57\end{array}$ & 0.127 & $\begin{array}{c}165.0 \\
\pm 26.46\end{array}$ & $\begin{array}{l}180.0 \\
\pm 8.16\end{array}$ & 0.346 \\
\hline
\end{tabular}

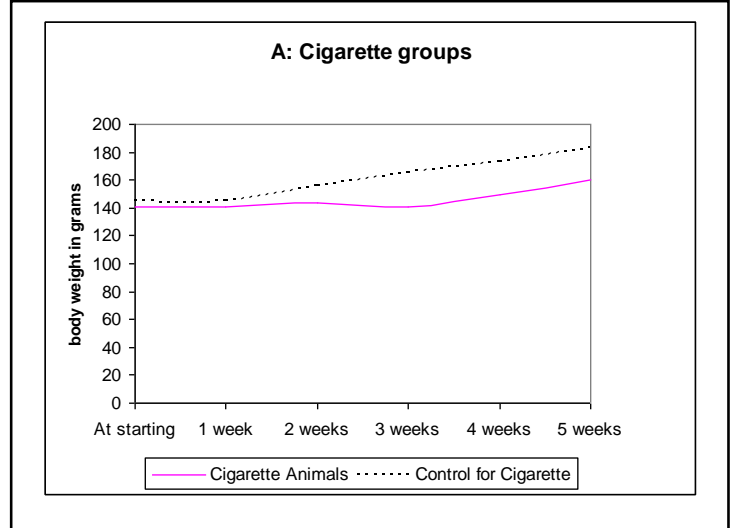

A

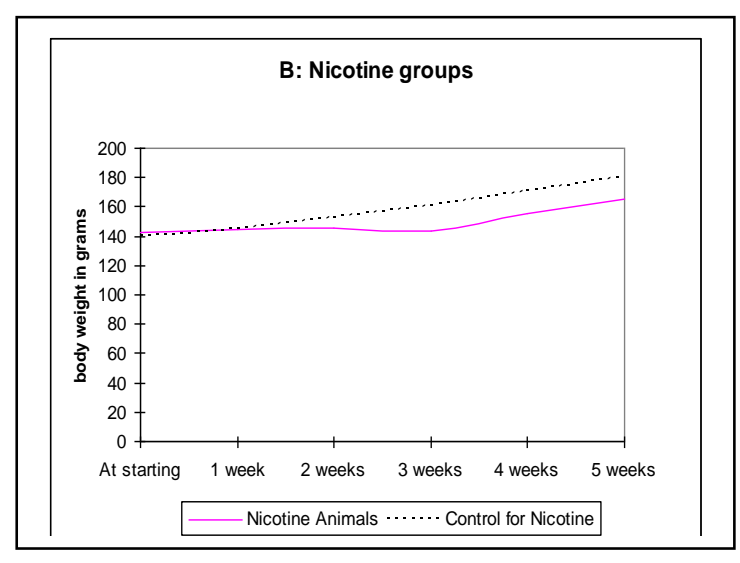

B

Fig. (1; A\&B): The mean body weight of cigarette and nicotine groups in relation tocontrol group during the experiment. 
Table2 The mean values of Optical Density of PAS reaction in different zones of hepatic lobules (in cigarette and nicotine animals)

\begin{tabular}{|c|c|c|c|c|c|c|}
\hline \multirow{2}{*}{ Groups } & \multirow{2}{*}{$\begin{array}{l}\text { Mean } \\
\text { O.D. of } \\
\text { hepatic } \\
\text { lobule } \\
\text { +S.D. }\end{array}$} & \multirow{2}{*}{$\begin{array}{l}\text { Mean } \\
\text { O.D. of } \\
\text { zone I } \\
\pm \text { S.D. }\end{array}$} & \multirow{2}{*}{$\begin{array}{l}\text { Mean } \\
\text { O.D. of } \\
\text { zone II } \\
\pm \text { S.D. }\end{array}$} & \multirow{2}{*}{$\begin{array}{l}\text { Mean } \\
\text { O.D. of } \\
\text { zone III } \\
\pm \text { S.D. }\end{array}$} & \multicolumn{2}{|c|}{$\begin{array}{c}\text { One Way ANOVA } \\
\text { between zones }\end{array}$} \\
\hline & & & & & $\mathbf{F}$ & $\mathbf{P}$ \\
\hline I & $0.42 \pm .01$ & $0.41 \pm .00$ & $0.42 \pm .00$ & $0.43 \pm .00$ & 42.16 & 0.000 * \\
\hline II & $0.38 \pm .01$ & $0.37 \pm .00$ & $0.38 \pm .01$ & $0.40 \pm .00$ & 33.70 & $0.000^{*}$ \\
\hline III & $0.31 \pm .02$ & $0.29 \pm .01$ & $0.31 \pm .01$ & $0.33 \pm .01$ & 14.79 & $0.000^{* *}$ \\
\hline$I V$ & $0.45 \pm .01$ & $0.47 \pm .01$ & $0.45 \pm .01$ & $0.44 \pm .00$ & 21.38 & $0.000 \#$ \\
\hline$V$ & $0.54 \pm .05$ & $0.54 \pm .05$ & $0.53 \pm .06$ & $0.54 \pm .08$ & 0.012 & 0.988 \\
\hline \multicolumn{7}{|c|}{ One Way ANOVA for lobules between groups $(F=114.86)-(P=0.000)$} \\
\hline VI & $0.41 \pm .01$ & $0.40 \pm .00$ & $0.41 \pm .01$ & $0.42 \pm .00$ & 22.68 & $0.002 \#$ \\
\hline VII & $0.37 \pm .02$ & $0.35 \pm .01$ & $0.37 \pm .01$ & $0.39 \pm .01$ & 37.57 & 0.000 * \\
\hline VIII & $0.26 \pm .03$ & $0.23 \pm .03$ & $0.27 \pm .01$ & $0.28 \pm .01$ & 07.07 & $0.014^{* *}$ \\
\hline IX & $0.44 \pm .01$ & $0.45 \pm .01$ & $0.44 \pm .01$ & $0.43 \pm .00$ & 06.87 & $0.015^{* *}$ \\
\hline$X$ & $0.51 \pm .03$ & $0.51 \pm .03$ & $0.51 \pm .05$ & $0.50 \pm .02$ & 0.199 & 0.825 \\
\hline
\end{tabular}

- all groups.

The significance is between:

- all the three zones.

** zone 1 and zone 3 .

\# zone 1 and zone 3 \& zone 2 and zone 3.

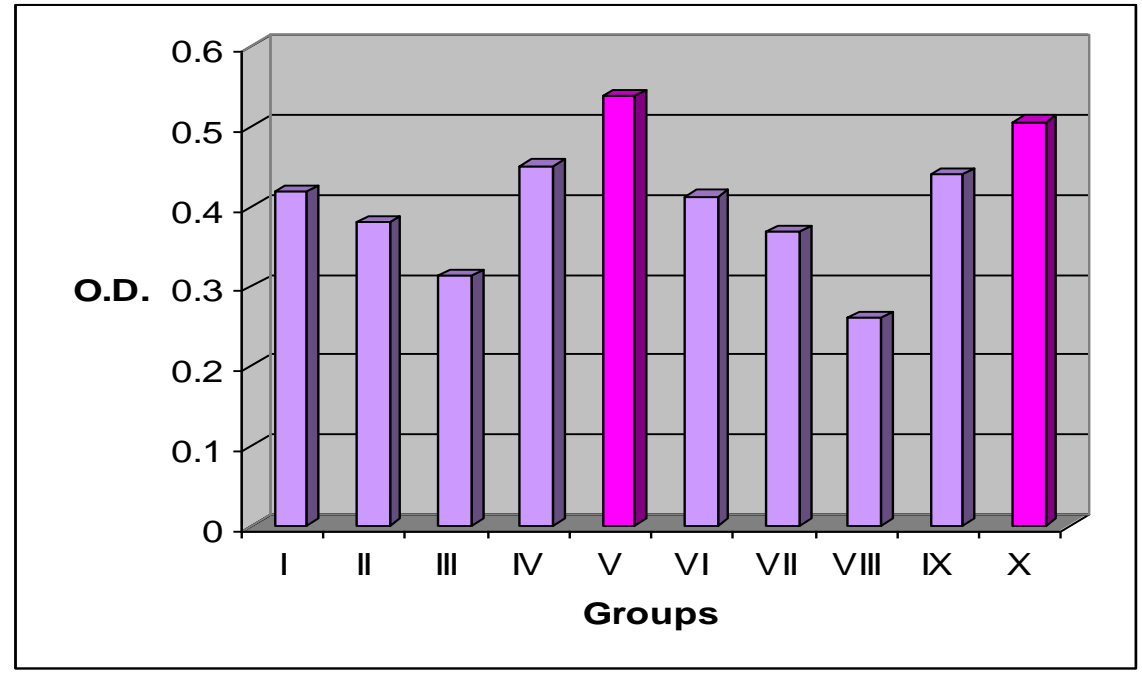

Fig. (2): The meane O.D. of PAS reaction (in all groups) 


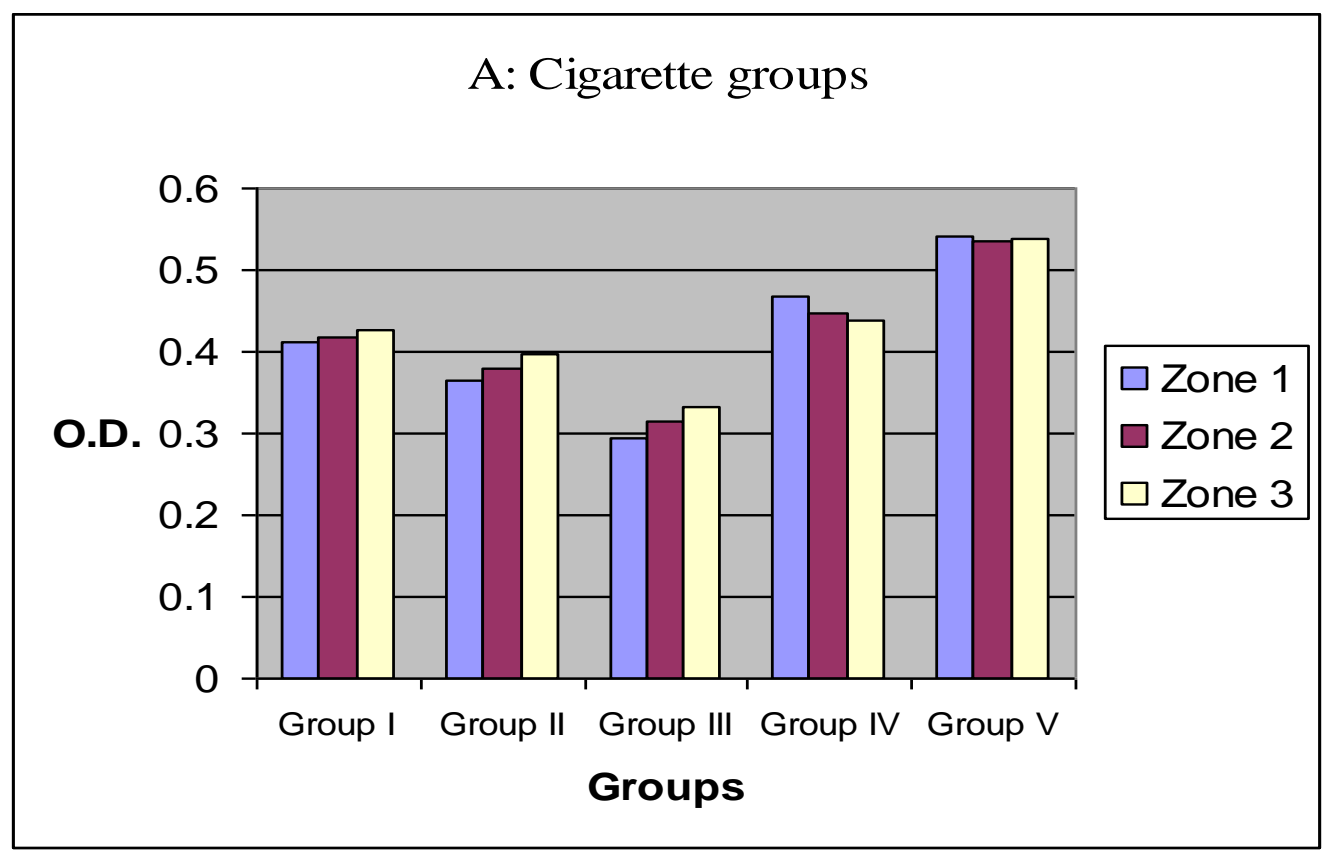

Fig. (3): The mean optical density of PAS reaction in cigarette group (in different zones of hepatic lobules of different groups)

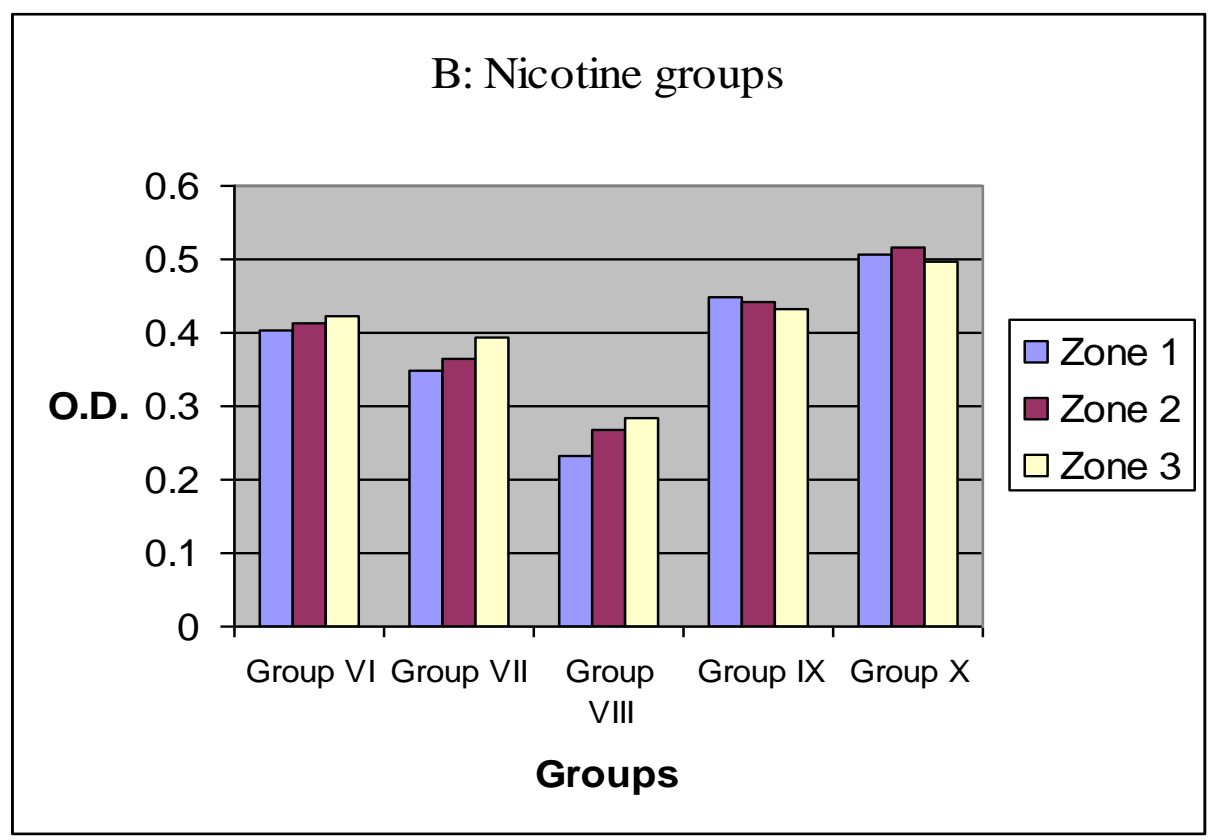

Fig. (4): The mean optical density of PAS reaction in nicotine group (in different zones of hepatic lobules of different groups) 


\section{PLATE I :}

A-Photomicrograph of the liver of a control rat showing normal hepatocytes ( $H \& E \quad x$ 400).

B-Photomicrograph of the liver of a rat from 3 weeks smoke inhalation group showing periportal fibrosis. Hepatocytes show pyknotic nuclei and vacuolated cytoplasm. (Masson trichrome x400).

C-Photomicrograph of the liver of a control rat showing normal PAS react ion in hepatocytes (PAS x400).

D-Photomicrograph of the liver of a rat one week after nicotine injection showing marked cellular infiltration.

( $H \& E \quad x$ 400).

E- Photomicrograph of the liver of a control rat showing the normal thin collagen fibers of the hepatic stroma (Masson trichrome x250).

F- Photomicrograph of the liver of a rat 3 weeks after nicotine injection showing dilated congested portal vein and perip ortal fibrosis.(Masson trichrome $\mathrm{x} 400$ ).

\section{PLATE II :}

A- Photomicrograph of the liver of a rat one week after nicotine injection sho wing hepatocytes with pyknotic nuclei ,portal vein dilatation and many Von Kupffer cells. ( H\&E x 250).

B- Photomicrograph of the liver of a rat from one week smoke inhalation group showing normal hepatocytes in zone III and degenerated hepatocytes in zone II . ( H\&E x 400).

C- Photomicrograph of the liver of a rat 2 weeks after nicotine injection show ing hepatocytes with marked cytopla smic vacuolation and nuclear pyknosis in all hepatic zones. ( H\&Ex 250).

D- Photomicrograph of the liver of a rat from 2 weeks smoke inhalation group showing marked necrosis of hepato cytes. ( $H \& E$ x 250).

E- Photomicrograph of the liver of a rat 3 weeks after nicotine injection show ing hepatocytes with marked cytopla smic vacuolation and nuclear pyknosis in all hepatic zones ( H\&Ex 400).

F- Photomicrograph of the liver of a rat from 3 weeks smoke inhalation group showing congested central vein surrou nded with degenerated hepatocytes.

( $H \& E \quad x$ 400).

\section{PLATE III :}

A- Photomicrograph of the liver of a rat 2 weeks after recovery from nicotine injection showing cellular infiltration in the portal tract and regenerating hepat ocytes . ( H\&E x 250)

B- Photomicrograph of the liver of a rat 2 weeks after recovery from smoke inhalation showing dilated central vein surrounded with regenerating hepato cytes and many Von Kupffer cells. ( $H \& E \quad x \quad 250$ )

C- Photomicrograph of the liver of a rat 2 weeks after recovery from nicotine injection showing weak PAS positive reaction.(PAS x250)

D- Photomicrograph of the liver of a rat 2 weeks after recovery from smoke inhalation showing weak PAS positive reaction.(PAS x250)

E- Photomicrograph of the liver of a rat 3 weeks after recovery from nicotine injection showing moderate PAS reaction .Cellular infiltration is seen in the portal tract.(PAS x400).

F- Photomicrograph of the liver of a rat 3 weeks after recovery from smoke inhalation showing moderate PAS reaction. .(PAS x400). 


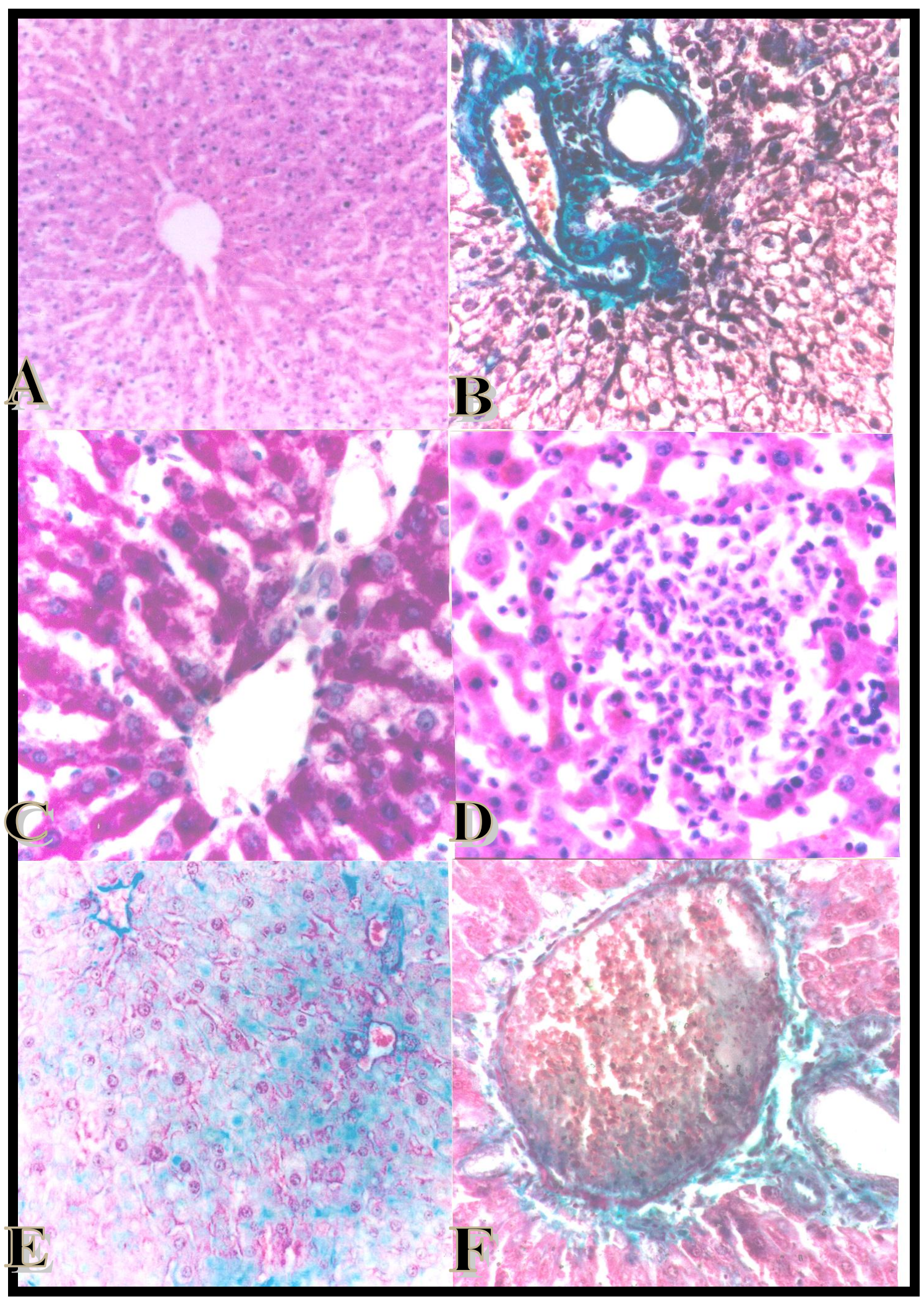

PL ATE I 


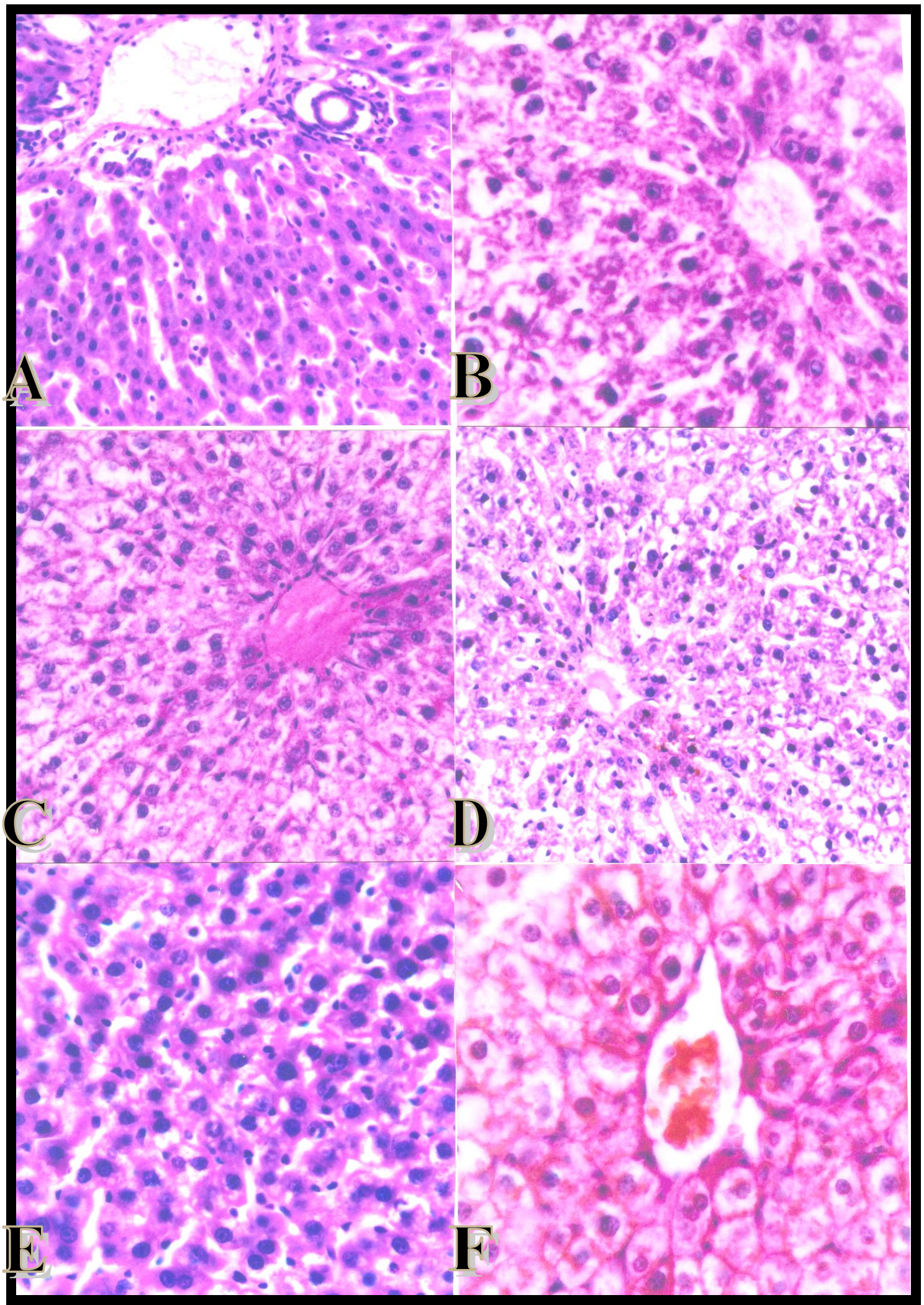

\section{PLATE II}




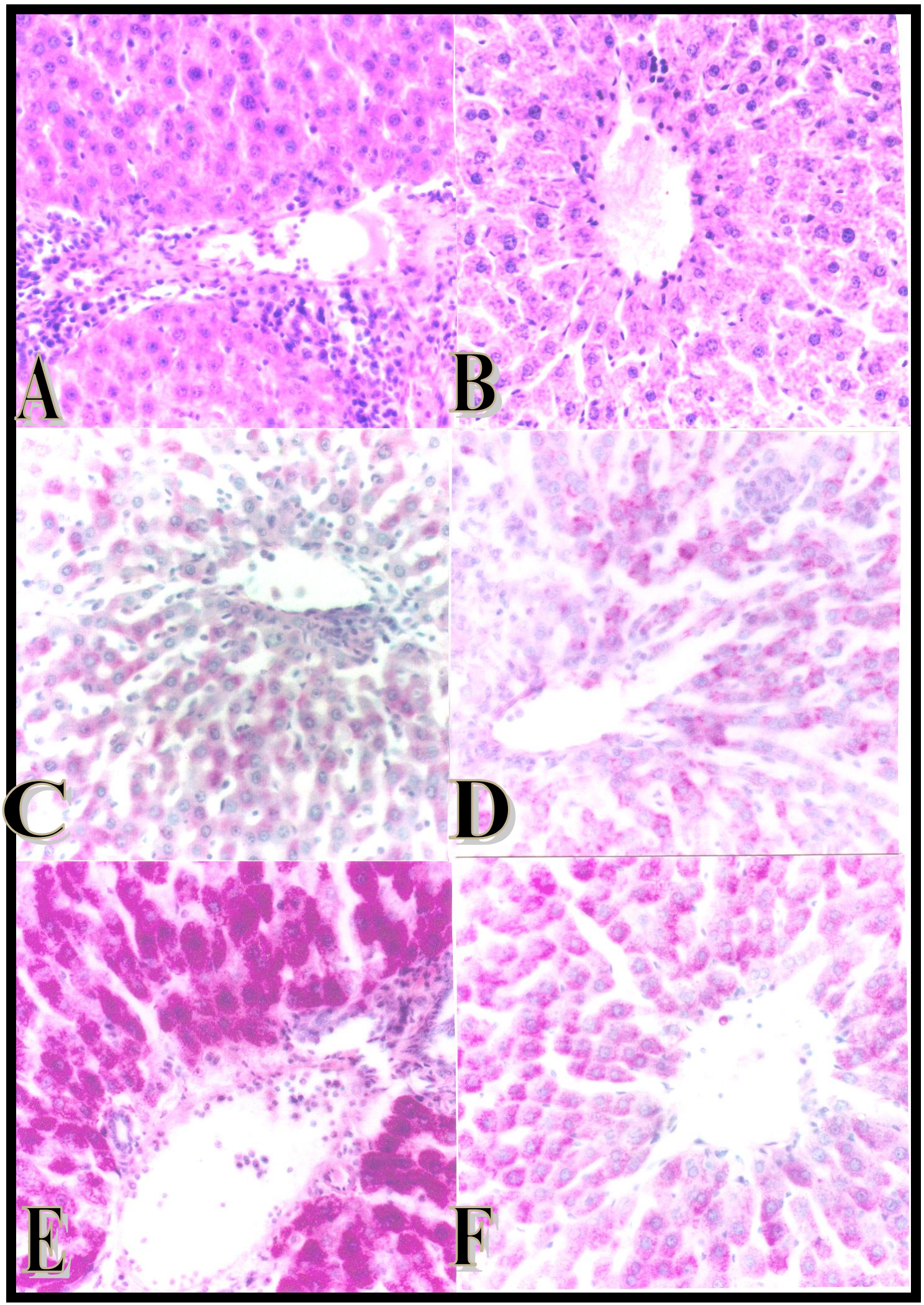

PLATE III 


\section{Discussion}

Although cigarette smoking is well known by its serious impacts on the human health, the smoking habits are still more increasing among young adults especially in developing count ries (Benowitz, 1988). In the present study the effect of cigarette smoke inhalation versus nicotine injection was tried on adult male albino rats. The decrease in body weight of the experi mental animals, in this study, might be related to a diminished food consum ption caused by developed anorexia (Chowdhury et al., 1992) or due to increased lipoprotein lipase activity in adipose tissue, which provided a counter-regulatory role in weight gain (Ashakumary and Vijayammal,1997) The weight gain after cigarette smoke or nicotine cessation was explained by Zhang and Ratchffe, (1993) to be due to a decrease in the basal oxygen consumption, with no change in caloric intake or physical activity. The liver seemed to be the appropriate organ to give a true reflection to the extent of the toxicity caused by smoke inhalation or nicotine injection As shown in the present study, cigarette smoke inhala tion resulted in degeneration of the hepatocytes, expanded portal tracts with chronic infiltrating inflammatory cells and dilatation of the central veins .These changes were observed first at the periphery of the hepatic lobules (zone I) then extended to involve the whole lobule (zone II and zone III). The previous alterations were time depen dent and when compared with the effects of nicotine administration, the above mentioned changes were apparent in a high aggravated form with groups of cigarette smoke inhalationThis may be attributed to the presence of many other toxic materials, rather than nicotine produced in cigarette smoke. This obvious hepatic toxicity following nicotine injection and cigarette smoke inhalation, were previously reported in the work of Wahba and Ziada (1992). The increase in the caliber of the blood vessels was recorded as an obvious manifestation of nicotine treatment. The progressive dilatation of the vessels in the liver could be considered as a reaction change that might be related to increased levels of prostaglandin (PG) synthesis where these PGs induced smooth relaxation and consequent vasodilatation either directly or through releasing other vasodilator substances in blood (Backhle et al., 1979). Walter and Israel (1996) explained the dilatation and congestion of the portal veins by the portal hypertension caused by obstruction at the sinusoidal level as a result of degenerating ballooning hepatocyts. The presence of infiltrating lymphocytes, mainly in the portal areas in addition to the peripheral parts of the lobules, might be explained as a defense reaction of the lobule in response to the toxicity of inhaled cigarette smoke or injected nicotine, being metabolized in the liver (Gorrod et al., 1975). The efficiency of the hepatocytes to perform their metabolic functions is dependent on the incoming blood, which is influenced by the availability of oxygen and nutrients. This in turn is affected by the presence of toxic substances in the blood that bathes the hepatocytes. This explains the vacuolation of cytoplasm and also could explain the affection of the peripheral hepatocytes of zone I before the central ones in zones II and III. Zhang and Ratchffe, (1993) repor ted that, hypoxia might lead to disturbance of ionic milieu of the cell with cons equent retention of water and sodium leading to cellular swelling. The darkly stained eosinophilic cytoplasm detected in some necrotic hepatocytes in the present study could be ascribed to depletion of basophilic ribosomes or ribonucleoprotein as reported by Jones 
and Mills (1984). It would be appropriate to account from the present results, that upon withdrawal of nicotine, the liver managed to recover from its toxic lesions. Recovery was observed by regeneration, as the remaining liver cells had undergone division and replaced those, which had been destroyed. Since, the reticulin framework of each lobule was undamaged; the resulting healing left a perfectly normal architecture . Haschek and Rousseaux, ( 1991) reported similar results . Normally glycogen began to appear in the periphery of the hepatic lobule due to the fact that the cells in this portion were the first to come in contact with the nutrients carried by the portal blood. It seemed clear therefore, that a peripheral pattern of glycogen deposition was a sign of glycogenesis. On the other hand, central depletion pattern could express glycogenolysis (Popp and Cattly,1991). On such explanation, one could say that cigarette smoke inhalation or nicotine injection resulted in increased glycogenolysis. While after cessation of smoking and nicotine, glycogenesis started in the peripheral cells. The increase of PAS +ve material in the expanded portal tracts might be due to the large number of active infiltrating cells, mainly fibroblasts, with more deposition of PAS positive collagen fibers. The observed disturbance in carbohydrate metabolism could be a result of the hepatic damage and tissue injury caused by intoxication with nicotine and otherconstituents. In conclusion the occurrence of hydropic and fatty degenerations of liver cells at the end of the first week of this work, denotes the rapid onset of liver affection after inhalation of cigarette smoke or nicotine injection. Althougth a satisfactory recovery of the hepatocytes occurred after cessation of exposure other morphological alterations that occurred in the portal tracts did not show complete recovery. Therefore, there are reversible and irreversible hepatic changes. The lymphocytic infiltration of portal tracts might play a role in the reversible hepatic changes. In the current study, the marked morpholo gical and histochemical changes in the liver has confirmed that the contents of inhaled cigarette smoke including nicotine and other hazardous compo unds, are very dangerous to the liver than the injected nicotine alone.

\section{References}

1. Armitage, A.K.; Dollery, C.T.; George, C.F. and Houseman, T.H. (1975): The absorption and metabolism of nicotine from cigarettes. Brit. Med. J. 4:313.

2. Ashakumary L., and Vijayammal P.(1997): Effect of nicotine on lipoprotien metabolism in rats Lipids 32(3):311-5

3. Auerbach, O. and Garfinkell, L. (1989): Histologic changes in the urinary bladder in relation to cigarette smoking. Cancer, 64, 983-987.

4. Backhle, Y.S.; Hartiala, J.; Toivonan, H. and Votilla, P. (1979): Effects of cigarette smoke on the metabolism of vasoactive hormones in the isolated rat lung. Br. J. Pharmacol, 65, 495-499.

5. Benowitz, N.L. (1986): Clinical pharmacology of nicotine. Ann. Rev. Med., 37:21-32.

6. Benowitz, N.L. (1988): Pharmacologic aspects of cigarette smoking and nicotine addiction. The New England Journal of Medicine, 319, 1318-1330.

7. Byrd, M. (1991) : Smokers need more vitamin C Medical Times 2,12

8. Carney, C.M. and Goldberg, A.P. (1984): Weight gain after cessation of cigarette smoking. N. Engl. J. Med., 310 (10), 614-616.

9. Chang, L.; Hosotaml, R. and Rayford, P.L. (1990): Metabolic and pathologic effect of nicotine on gastrointestinal tract and pancreas of rats. Pancreas 5, 222-229. 
10. Chowdhury, P.; Rayford, P.L. and Chang, L.W. (1992): Induction of pancreatic acinar pathology via inhalation of nicotine. Soc. Exp. Biol. Med., 201, 159-164.

11. Dalbey, W.K.; Netteshein, P.; Caton, J.E. and Guerin, M. (1980): Chronic inhalation of cigarette smoke by $\mathrm{F}_{344}$ rats. Natle Cancer Institute, 64, 112118.

12. Daniell, H.W. (1976): Osteoporosis of the slender smoker. Arch. Intern. Med., 136, 298-304.

13. Drury R.A.B. and Walington, E.A. (1976): Carleton's Histology Technique. $4^{\text {th }}$ edition. New York, p. 126 and 178.

14. Dubick, M.A.; Conteas, C.N. and Billy, M.T. (1987-a): Raised serum concentrations of pancreatic enzymes in cigarette smokers. Gut; 28, 330-335.

15. Goodman, A.G. and Gilman, S.L. (1991): The pharmacological basis of the therapeutics. Mac Millan Publishing Co. Inc., New York, $8^{\text {th }}$ edition.

16. Gorrod, J.W. and Jenner, P. (1975): The metabolism of tobacco alkaloids. In Essays in Toxicology, 6, 35-78, New York.

17. Haschek, W.M. and Rousscaux, C.G. (1991): Handbook of toxicologic pathology. Academic Press, California, $1^{\text {st }}$ edition.

18. Hass, G. Landerholm, W. and Hemmens, A.(1966) :Production of calcific atherosclerosis and thromboar teritis with nicotine, vitamin $\mathrm{D}$ and dietary cholesterol .Am. J . Path. ,49(4) 739

19. Henningfield, J.E.; Coslett, R.N. and Clark, T. (1988): Nicotine dependence: Interface between tobacco and tobacco-related disease. Chest. (Suppl), 93, 2:37.
20. Jones, M. and Mills, S. (1984): The liver cell. Cellular defects in disease. Lancet, 2, 319-325.

21. Kaufman, M. (1980): Cigarette smoking and age at natural menopause. Am. J. Public Health, 70, 420-422.

22. Knudson, R.J.; Knudon, D.E. and Kaltenborn, W.T. (1989a): Subclinical effects of cigarette smoking. Chest., 95:512.

23. Konturek, S.J.; Solomon, T.E.; McGreight, W.G.; Johnson, L.R. and Jacobson, E.G. (1971): Effects of nicotine on gastrointestinal secretions. Gatroenterolgy, 60, 1098-1105.

24. Popp,J.A. AND Cattley,R.C.(1991) :Hepatobiliary system in :Handbook of toxicology and pathology Academic press,inc. London 14,p.279

25. Rosenberg, J.; Bonwitz, N.L.; Jacob, and Wilson, K.H. (1980): Disposition kinetics and effects of intravenous nicotine. Clin. Pharmacol. Ther., 28, 516-522.

26. Sankaran, H.; Lewin, M.B.; Wong, A. and Martin, L. (1985): Irreversible inhibition by acetaldehyde of cholecys tokinin induced amylase secretion for isolated rat pancreatic acini. Biochem. Pharmacol., 34, 2859-2863.

27. Wahba, S.R. Ziada, I.A. (1992): The interactive effect of caffeine and nicotine on hepatic proteins. Egypt. J. Histol., 15(2), 431-441.

28. Walker, T.R. and Kiefer, J.E. (1979): Ciliostatic components in the gas phase of cigarette smoke. Science, 153:1248.

29. Walter, J.B. and Israel, M. (1996): General pathology. Churchill Livingstone, New York, $7^{\text {th }}$ edition.

30. Zhang, and Ratchffe,J.M.(1993 ): Paternal smoking and birth weight.83(2),267-269 


\section{در اسة مقارنة لتأثثر النيكوتين علي كبد الفار الأبيض

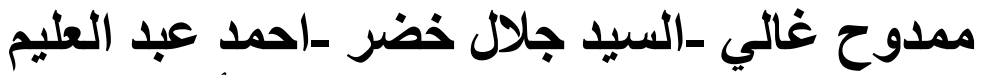 قسم الهينولوجيا كلية الطبـ بنين- جامعة الأزهر بالقاهرة}

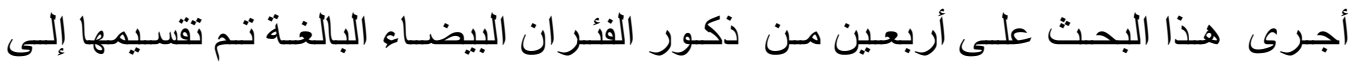

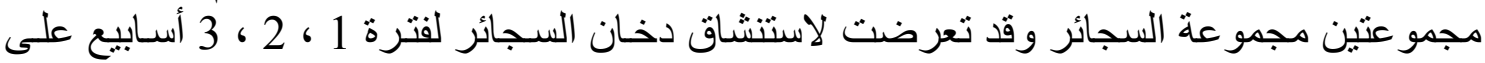

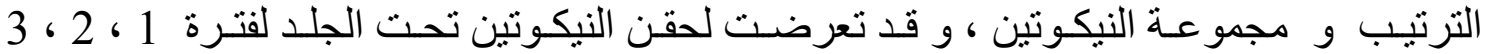

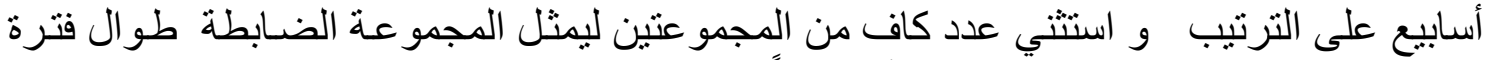

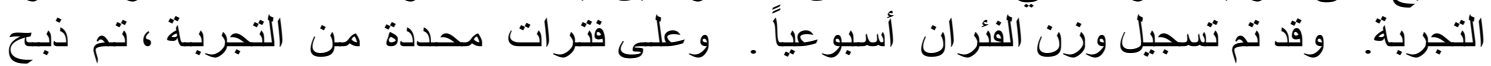

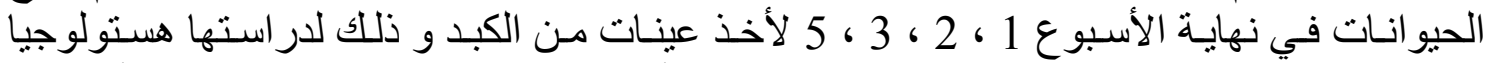

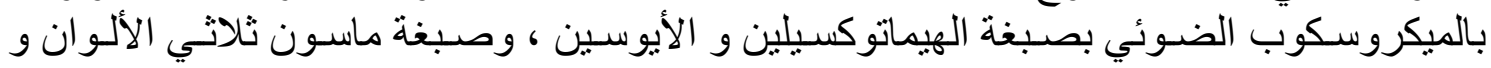
كذللك تفاعل شيف البير ايودي

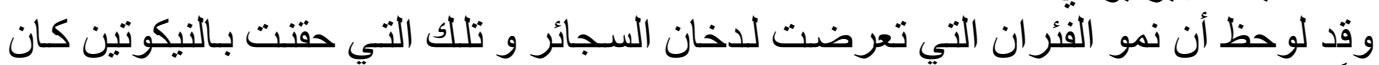

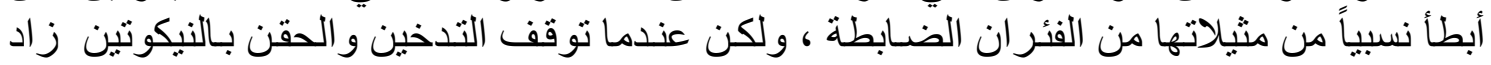

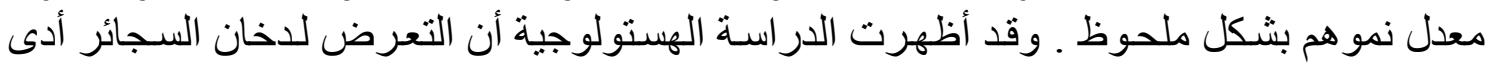

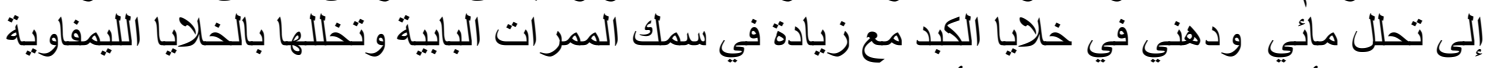

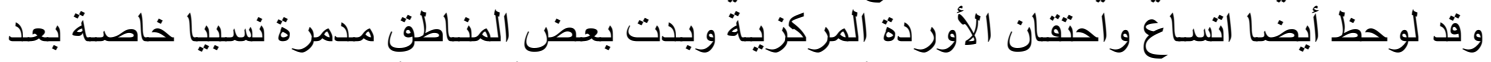

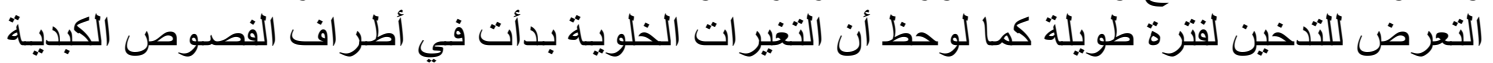

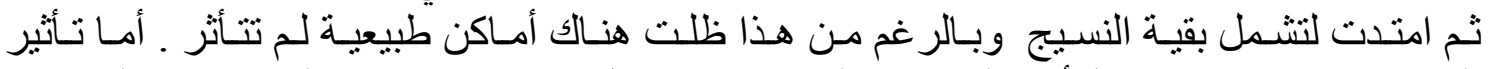

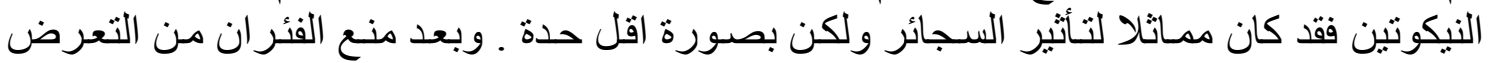

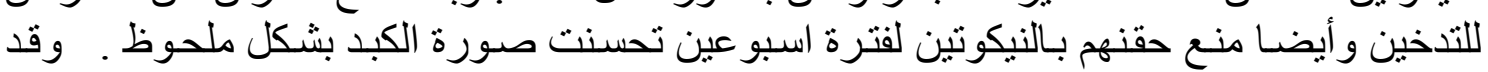

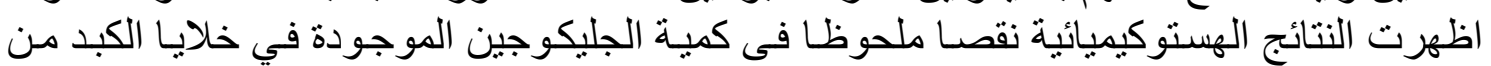

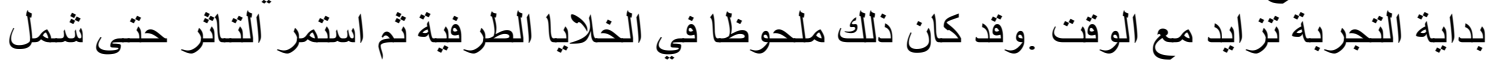

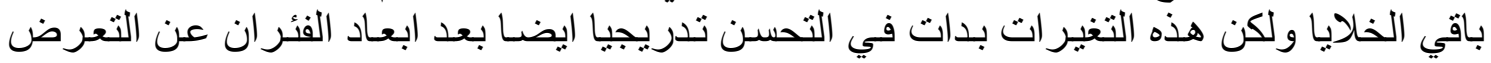

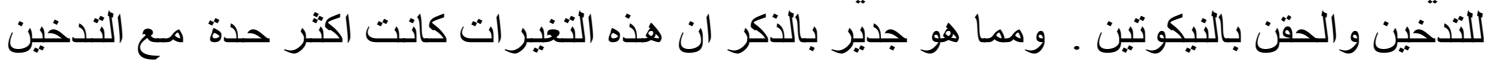

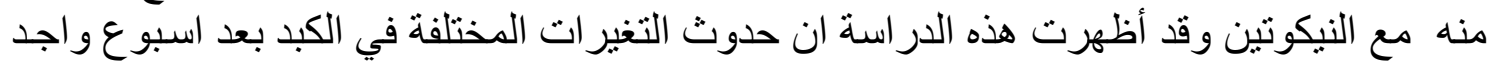

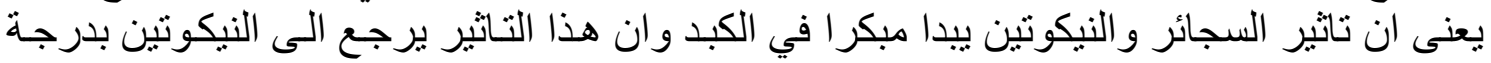

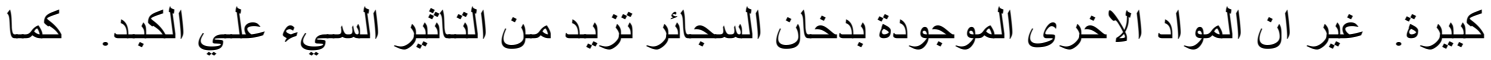

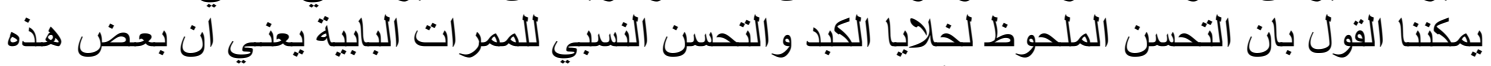

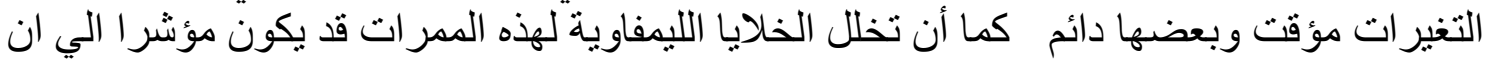

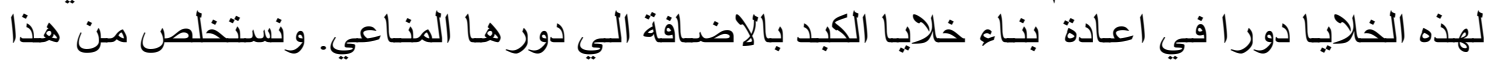

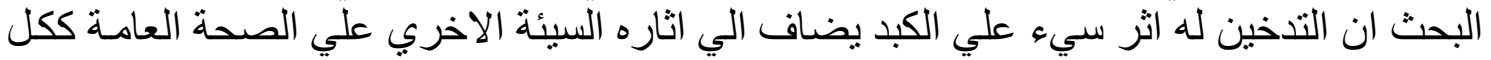
مما يستوجب الاققلاع عنه. 